\title{
Effects of changes in acid base and calcium concentration on fasting serum insulin, proinsulin, and glucose concentrations
}

\author{
W S A Smellie, J O'Donnell, H Davidson, J Couper, F C Logue
}

\begin{abstract}
Aims-To test the hypothesis that alterations in acid base or calcium concentration may affect proinsulin processing or the insulin secretion mechanism.

Methods-Changes in proinsulin secretion or cleavage were assessed by measuring serum intact proinsulin and immunoreactive insulin concentrations in three models of acid base and calcium disturbance: (1) subacute changes in acid base status in six volunteers who received oral placebo, ammonium chloride, or sodium bicarbonate for three five day periods; (2) acute changes in calcium concentration in eight subjects who received $25 \mathrm{mmol}$ oral calcium; (3) chronic changes in calcium concentration in seven patients with primary hyperparathyroidism and five with pseudohypoparathyroidism.

Results-Acid base changes were confirmed by rises in serum bicarbonate concentrations $(p<0.01)$. No changes in serum insulin, intact proinsulin, or the proinsulin:insulin molar ratio were found. Serum calcium concentrations increased $(2.49 v 2.38 \mathrm{mmol} / \mathrm{l} ; \mathrm{p}<0.05)$ and parathyroid hormone concentrations decreased (1.1 $v 1.9 \mathrm{pmol} / 1 ; \mathrm{p}<0.01)$ two hours after acute calcium loading. There were no significant differences in serum glucose, insulin, or intact proinsulin concentrations. Fasting proinsulin concentrations were significantly lower in the hyperparathyroid group $(1 \cdot 1 \quad v \quad 2 \cdot 1 \mathrm{pmol} / 1$; p $<0.05)$ and increased significantly after parathyroidectomy $(2.1 \quad v \quad 1.1 \quad \mathrm{pmol} / 1$; p $<0.05$ ).

Conclusions-The results indicate that subacute acid base changes do not affect proinsulin cleavage. Although acute calcium loading has no demonstrable effect, chronic hypercalcaemia may influence the mechanism of insulin secretion.
\end{abstract}

Institute of Biochemistry, Infirmary, Castle Street, Glasgow G4 OSF

W S A Smellie J O'Donnell H Davidson J Couper F C Logue Correspondence to: Dr W S A Smellie

Accepted for publication 24 March 1994
(F Clin Pathol 1994;47:982-985)

The two endopeptidases responsible for the cleavage of native intact proinsulin to 32-33 and 65-66 split proinsulins have been characterised and shown to be calcium and $\mathrm{pH}$ dependent. $^{12}$ Subsequent cleavage by carboxypeptidase $\mathrm{H}$ to des $31-32$ and des 64-65 proinsulin is also a $\mathrm{pH}$ dependent process. ${ }^{3}$

Recent changes in immunoassay technology, particularly the advent of biosynthetic proinsulin standards, and monoclonal antibody technology have led to the development of oligospecific assays capable of detecting intact proinsulin, 32-33 and 65-66 split proinsulins, ${ }^{4}$ and therefore to investigation of the insulin secretory mechanism in vivo.

Calcium homeostasis is disturbed in diabetes mellitus both in man and in rats with streptozotocin induced diabetes. ${ }^{56}$ In man decreased plasma calcium, hypocalciuria, and decreased bone formation have been recorded. ${ }^{67}$ As defects in proinsulin cleavage to insulin, leading to increased circulating concentrations of proinsulin conversion intermediates, have been proposed as a possible aetiological mechanism in non-insulin dependent diabetes, ${ }^{8}$ this would be a possible site for calcium and glucose homeostasis to interact. Acute effects of calcium loading, which might be expected to influence calcium dependent secretion, were investigated in outpatients with nephrolithiasis undergoing metabolic assessment, and the chronic effects of altered calcium homeostasis were studied using the models of pseudohypo- and hyperparathyroidism. Chronic disturbances of calcium metabolism would be expected to result in more sustained changes in intracellular calcium concentrations and more profound effects on calcium dependent enzymatic or secretion mechanisms. Parathyroid hormone may also directly increase cell membrane permeability to calcium ${ }^{9}$ and may therefore act directly to increase intracellular calcium concentrations.

We therefore tested the hypothesis that acute or subacute changes in acid base or calcium concentrations may influence proinsulin cleavage and glucose homeostasis. Proinsulin cleavage was assessed by measuring intact proinsulin, immunoreactive insulin, and the proinsulin:insulin molar ratio.

\section{Methods}

ACID BASE LOADING

Six healthy adult male volunteers were studied for three five day periods. Dietary calcium intake was controlled at $17 \mathrm{mmol} /$ day to avoid any possible interference on the proinsulin cleavage mechanisms by changing dietary serum calcium intake. The three periods were randomly ordered in each subject and comprised: (1) diet; (2) diet plus ammonium chloride $1.78 \mathrm{mmol} / \mathrm{kg} /$ day; and (3) diet plus sodium bicarbonate $3.56 \mathrm{mmol} / \mathrm{kg} /$ day.

A washout period of at least 48 hours was allowed between treatment periods. Capsules 
Table 1 Serum electrolyte and urine pH data in six volunteers during the three five day loading periods

\begin{tabular}{lccc}
\hline Serum (mmol/l) & Control & Acid & Base \\
\hline Bicarbonate $(\mathrm{mmol} / \mathrm{l})$ & $27 \cdot 0$ & $23 \cdot 7^{\star}$ & $28 \cdot 7$ \\
Potassium $(\mathrm{mmol} / \mathrm{m})$ & $4 \cdot 28$ & $4 \cdot 30$ & $4 \cdot 10$ \\
Adjusted calcium $(\mathrm{mmol} / \mathrm{l})$ & $2 \cdot 39$ & $2 \cdot 37$ & $2 \cdot 39$ \\
Creatinine $(\mu \mathrm{mol} / \mathrm{l})$ & $94 \cdot 2$ & $89 \cdot 2$ & $93 \cdot 3$ \\
Urine $\mathrm{pH}$ & $6 \cdot 23$ & $4 \cdot 98^{\star}$ & $7 \cdot 77^{\star}$ \\
\hline
\end{tabular}

${ }^{\star} \mathrm{p}<0.01$ versus control value.
ASSAYS

Intact proinsulin and insulin were measured using a two-site immunoradiometric assay (IRMA) and polyclonal radioimmunoassay (RIA), respectively, as described before. ${ }^{11}$ Characteristics of the two assays are as follows:

\section{Insulin RIA}

A typical calibration curve shows a seven-fold signal change over the standard concentration range $(0-757 \mathrm{pmol} / \mathrm{l})$. The minimum detection limit $(22 \%$ coefficient of variation (CV) via precision profile) is $26.5 \mathrm{pmol} / 1$, and the working range $(<10 \% \mathrm{CV})$ is $76-380 \mathrm{pmol} / 1$. Cross-reactivity with intact proinsulin is 80-107\%.

\section{Proinsulin IRMA}

The intact proinsulin IRMA shows a 60 -fold signal change from $0-334 \mathrm{pmol} / \mathrm{l}$. The minimum detection limit is $0.6 \mathrm{pmol} / 1$ (22\% via the precision profile) and the working range $(<10 \% \mathrm{CV})$ is 1.0 to $>334 \mathrm{pmol} / \mathrm{l}$. The recovery of exogenous proinsulin $(18.2 \mathrm{pmol} / \mathrm{l})$ from serum is quantitative (mean $103 \%$, range $97 \cdot 3-109 \cdot 9 \%, n=10$ ). Cross-reactivity with 32-33 split and des 31-32 split proinsulin is $<2 \%$.

\section{Others}

Glucose was measured by a hexokinase enzymatic method on a Hitachi 747 autoanalyser. Calcium was measured by an o-cresolpthalein method, bicarbonate by a phenolphthalein colourimetric method, creatinine by a modified Jaffé reaction, and sodium and potassium by ion selective electrodes, using reagents supplied by Boehringer Mannheim, Lewes, Sussex) on a SMAC II autoanalyser. Parathyroid hormone was assayed by the 1-84 N-terminal immunoradiometric assay described by Logue. ${ }^{12}$

Results were analysed by Student's $t$ tests (normally distributed data) or Wilcoxon signed rank test and Kruskall-Wallace analysis for non-parametric data. The proinsulin: insulin molar ratio was derived as the ratio of proinsulin (pmol/l) and insulin (pmol/l). Insulin values were converted from $\mathrm{mU} / 1$ to $\mathrm{pmol} / \mathrm{l}$ by multiplying by $7 \cdot 57$, assuming a molecular weight for insulin of 5734 .

\section{Results}

\section{ACID BASE LOADING}

Results from the assessment of acid-base state are shown in table 1 . Significant changes in serum bicarbonate concentration and in 1-a-hydroxy
supplements.

Table 2 Mean fasting serum insulin, proinsulin, and glucose concentrations measured on days 3, 4, and 5 during control, acid loading, and base loading periods in six healthy volunteers ( $1 \mathrm{mU}$ insulin $=0.132 \mathrm{pmol}$ )

\begin{tabular}{|c|c|c|c|c|c|c|c|c|c|}
\hline \multirow[b]{2}{*}{ Case No } & \multicolumn{3}{|c|}{ Insulin (mU/l pmolll) } & \multicolumn{3}{|c|}{ Proinsulin (pmol/l) } & \multicolumn{3}{|c|}{ Glucose (mmol/l) } \\
\hline & Control & Acid & Base & Control & Acid & Base & Control & Acid & Base \\
\hline $\begin{array}{l}1 \\
2 \\
3 \\
4 \\
5 \\
6\end{array}$ & $\begin{array}{r}<3.5 \\
7.0 \\
12.8 \\
30.9 \\
9.5 \\
5.2\end{array}$ & $\begin{array}{r}3 \cdot 1 \\
3 \cdot 5 \\
9 \cdot 7 \\
30 \cdot 6 \\
4.6 \\
11 \cdot 2\end{array}$ & $\begin{array}{r}10 \cdot 3 \\
6 \cdot 9 \\
10 \cdot 2 \\
26 \cdot 2 \\
7 \cdot 7 \\
8 \cdot 8\end{array}$ & $\begin{array}{l}1.5 \\
1.2 \\
1.7 \\
1.7 \\
1.3 \\
1.7\end{array}$ & $\begin{array}{l}1 \cdot 4 \\
1 \cdot 1 \\
2 \cdot 2 \\
1 \cdot 2 \\
0 \cdot 6 \\
2 \cdot 2\end{array}$ & $\begin{array}{l}1 \cdot 5 \\
1 \cdot 1 \\
2 \cdot 1 \\
0.7 \\
1 \cdot 3 \\
2 \cdot 0\end{array}$ & $\begin{array}{l}4 \cdot 7 \\
4 \cdot 7 \\
5 \cdot 7 \\
4 \cdot 5 \\
4 \cdot 4 \\
5 \cdot 1\end{array}$ & $\begin{array}{l}4 \cdot 3 \\
4 \cdot 4 \\
4 \cdot 2 \\
5 \cdot 3 \\
4 \cdot 5 \\
5 \cdot 0\end{array}$ & $\begin{array}{l}4 \cdot 6 \\
4 \cdot 5 \\
4 \cdot 3 \\
4 \cdot 6 \\
4 \cdot 6 \\
4 \cdot 3\end{array}$ \\
\hline
\end{tabular}



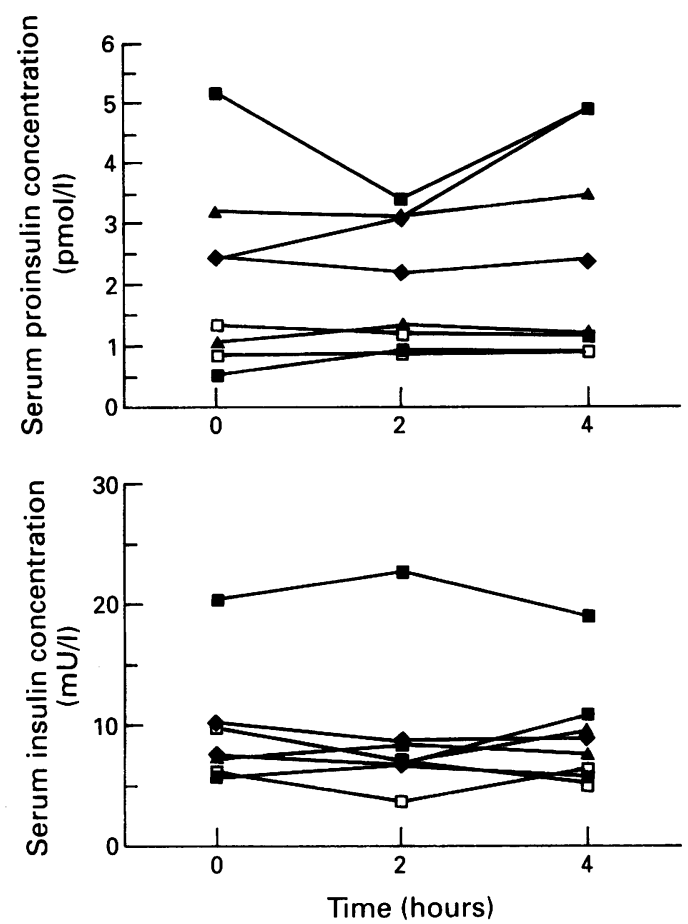

Figure 1 Serum insulin and proinsulin concentrations in eight subjects, before and two and four hours after oral administration of $25 \mathrm{mmol}$ calcium supplementation (Sandocal).

urinary $\mathrm{pH}$ were found between all three study periods $(\mathrm{p}<0.01)$.

Immunoreactive insulin, intact proinsulin, and glucose results are shown in table 2 . Visual assessments of these results confirmed that although glucose concentrations were nearly normally distributed, serum insulin
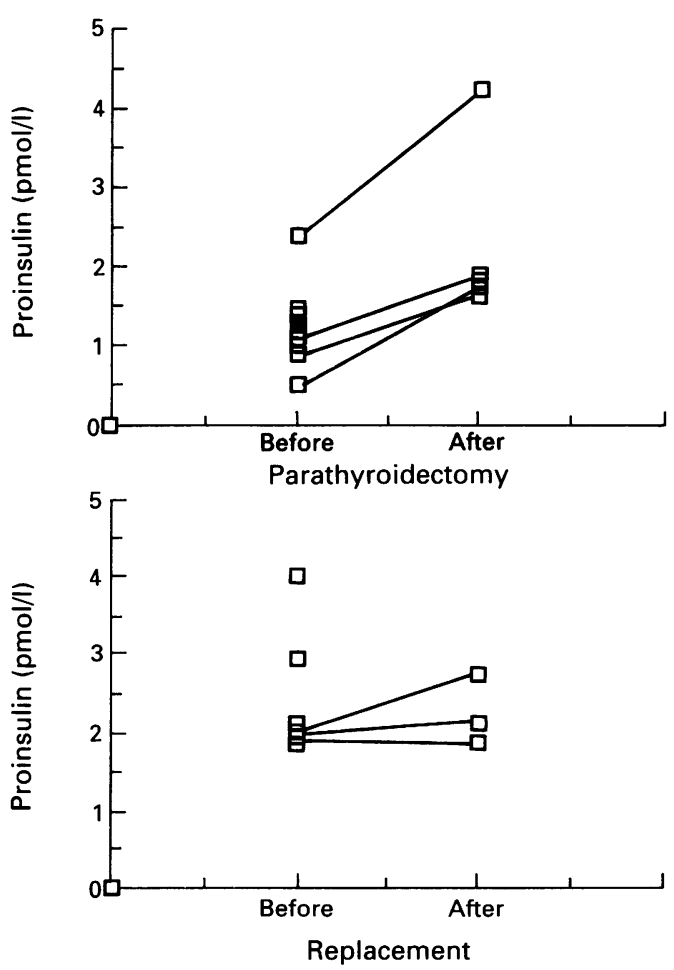

Figure 2 Fasting serum insulin and proinsulin concentrations in seven hyperparathyroid patients before parathyroidectomy, and in five patients, four after surger (mean of three values used for each point). and proinsulin concentrations were skewed. Individual results for insulin, proinsulin, and the proinsulin:insulin molar ratio (not shown) showed little variation and no trend in the direction of changes between the different treatment periods.

\section{CALCIUM LOADING}

Mean calcium concentrations rose significantly between zero and two hours $(2.38$ $\mathrm{mmol} / 1$ at zero hours, $2.49 \mathrm{mmol} / 1$ at four hours, and $2.39 \mathrm{mmol} / \mathrm{l}$ at four hours, $\mathrm{p}<$ 0.01 zero to two hours) and were matched by significant falls in parathyroid hormone (median values $1.9 \mathrm{pmol} / 1$ at zero hours, less than $0.05 \mathrm{pmol} / 1$ at two hours $(\mathrm{p}<0.01)$, and $1.1 \mathrm{pmol} / 1$ at four hours). Mean glucose results did not rise significantly over the four hours $(3.9 \mathrm{mmol} / 1$ at zero hours, $4.0 \mathrm{mmol} / 1$ at two hours, and $4.2 \mathrm{mmol} / 1$ at four hours).

Individual results for proinsulin and insulin are shown in fig 1. Median insulin results varied from $65 \cdot 1 \mathrm{pmol} / 1$ at zero hours to $58 \cdot 3$ $\mathrm{pmol} / 1$ at two hours, and $66.6 \mathrm{pmol} / 1$ at four hours. Proinsulin values varied from $2 \cdot 4$ $\mathrm{pmol} / \mathrm{l}$ at zero hours, to $2 \cdot 2 \mathrm{pmol} / 1$ at two hours, and $2.2 \mathrm{pmol} / 1$ at four hours. The median molar ratios varied from $3.6 \%$ at zero hours to $3.8 \%$ at two hours, and $3.3 \%$ at four hours (not significant).

\section{CHRONIC CALCIUM IMBALANCE}

Serum adjusted calcium decreased significantly in hyperparathyroid patients after parathyroidectomy $(2.3 v 2.9 \mathrm{mmol} / \mathrm{l} ; \mathrm{p}<$ $0.01)$. No significant changes in adjusted serum calcium were found in the three patients with pseudohypoparathyroidism after treatment with oral calcium and 1- $a$-hydroxy cholecalciferol, although calcium concentrations rose in only two of the three cases studied $(2.25 v 2.20 \mathrm{mmol} / \mathrm{l})$.

Individual results for fasting insulin and proinsulin concentrations are shown in fig 2 for hyperparathyroid patients. Mean fasting proinsulin concentrations in the hyperparathyroid group were significantly lower than in the other three groups $(p<0.01)$ and increased significantly following treatment $(p<0.05)$. No significant differences were present between the two groups following treatment. Insulin concentrations were not significantly different before or after treatment in either group, and no consistent trends were observed.

In the pseudohypoparathyroid group (fig 2) there were no trends or significant differences in proinsulin, insulin, or in the proinsulin: insulin molar ratio, before and after treatment $(2.5 v 2.9 \mathrm{pmol} / 1,87 \cdot 1 v 71.9 \mathrm{pmol} / 1$, and 2.2 $v 3.0 \%$, respectively)

\section{Discussion}

Although the enzyme system responsible for proinsulin cleavage is known to be $\mathrm{pH}$ dependent, moderate subacute changes in acid-base state in otherwise healthy subjects might have no demonstrable effect on intracellular $\mathrm{pH}$, and therefore on enzymatic cleavage. It 
remains possible, however, that chronic or severe changes in acid-base state may have a more pronounced effect. It is not practically possible to induce chronic acid-base disturbances in volunteers. Patients with severe acidosis or alkalosis almost invariably have renal or hepatic impairment, rendering interpretation of insulin and proinsulin measurements almost impossible. ${ }^{13} 14$

The calcium loading study confirmed physiologically important calcium loading, shown by increases in serum calcium and a reduction in serum parathyroid hormone concentrations. Results would indicate, however, that acute calcium loading does not influence insulin or proinsulin secretion or cleavage. Acute oral calcium loading would, however, be expected to influence only extracellular calcium concentrations; such changes would not be expected to influence intracellular or intraorganellar calcium concentration and, hence, enzymatic cleavage or secretion mechanisms.

Limited patient numbers were available for the study of chronic defects in calcium metabolism following treatment. Most cases of hyper- or hypocalcaemia involve coexistent diseases which also render interpretation of insulin concentrations in serum difficult. Data for samples before and after treatment were only available for four patients in the hyperparathyroid group and three in the hypoparathyroid group, restricting interpretation of these findings. The validity of each value is increased by using the mean of three readings, reducing any effects of short term variation among individuals found with these assays. ${ }^{11}$ Failure to show important changes in calcium in the pseudohypoparathyroid group precludes any conclusion being drawn from this small group. Further study with larger numbers of patients will be necessary.

In conclusion, moderate subacute changes in acid-base state do not have a measurable effect on proinsulin cleavage or insulin release. Similarly, acute calcium loading did not demonstrably affect insulin processing, although chronic hypercalcaemia may alter proinsulin cleavage or release.

We are most grateful to Dr D St J O'Reilly for his advice, to Miss P Price for her secretarial assistance, and to Drs R Scott and IT Boyle for allowing us access to patients' samples.

1 Davidson HW, Rhodes CJ, Hutton JC. Intraorganellar Ca and $\mathrm{pH}$ control proinsulin cleavage in the pancreatic B-cell via two distinct site-specific endopeptidases. Nature 1988;333:93-6.

2 Given BD, Cohen RM, Shoelson SE, Frank BH, Rubenstein AH, Tager HS. Biochemical and clinica implications of proinsulin conversion intermediates. f Clin Invest 1985;76:1396-405.

3 Davidson HW, Hutton JC. The insulin-secretory-glanule carboxypeptidase $\mathbf{H}$. Purification and demonstration of involvement in proinsulin processing. Biochem $\mathcal{F} 1987$; 245:575-82.

4 Sobey WJ, Beer SF, Carrington CA, Clark PMS, Frank BH, Gray IP, et al. Sensitive and specific two-site immunoradiometric assays for insulin proinsulin 65-66 immunoradiometric assays for insulin proinsulin 65-66

5 De Fronzo RA, Cooke CR, Andres R, Faloona GR, Davis PJ. The effect of insulin on renal handling of sodium, potassium, calcium and phosphate in man. $f$ Clin Inves 1975;55:845-55.

6 Frazer TE, White NH, Hough S, Santiago JV, McGee BR Bryce $G$, et al. Alterations in circulating vitamin D metabolites in the young insulin-dependent diabetic. $\ngtr$ Clin Endocrinol Metab 1981;53:1154-9.

7 Willis RG, Green R, Gordon C. The influence of glucose and insulin on calcium excretion in the urine. In: Schwille PO, Smith LH, Robertson WG, et al, eds. Urolithiasis and related clinical research. New York: Plenum Press, 1985:209-12.

8 Temple RC, Carrington CA, Luzio SD, Owens DR Schneider AE, Sobey WJ, et al. Insulin deficiency in non insulin-dependent diabetes. Lancet 1989;i:293-5.

9 Parsons JA, Robinson CJ. Calcium shift into bone causing transient hypocalcaemia after injection of parathyroid hormone. Nature 1971;230:581-2.

10 Chase LR, Melson GL, Aurbach GD. Pseudohypoparathyroid: Defective excretion of $3^{\prime} 5^{\prime}-A M P$ in response to parathyroid hormone. $\mathcal{f}$ Clin Invest 1969 48:1832-44.

11 Smellie WSA, McConway M, O'Donnell JG, Couper J, O'Reilly D St J. A comparison of inter-individual variability of fasting serum intact proinsulin and insulin concentrations. Communications in Laboratory Medicine 1993;5:15-20.

12 Logue FC, Perry B, Chapman RS, Milne I, James K Beastall GH. A two-site immunomeric assay for PTH (1-84) using $\mathrm{N}$ and $\mathrm{C}$ terminal specific monoclona antibodies. Ann Clin Biochem 1991;28:160-6.

13 De Fronzo RA. Pathogenesis of glucose intolerance in uraemia. Metabolism 1979;27(Suppl 2):1866-80.

14 Johnston DG, Alberti KGMM, Faber OK, Binder C, Wright R. Hyperinsulinism of hepatic cirrhosis: diminished degradation or hypersecretion. Lancet 1977; $\mathbf{i}$ 10-2. 